\title{
Antifungal activity of Moroccan plants against citrus fruit pathogens
}

\author{
N. Ameziane, H. BoubaKeR*, H. Boudyach, F. Msanda, A. Jilal, A. Ait Benaoumar \\ Laboratoire de Biotechnologie et de Valorisation des Ressources Naturelles, Faculté des Sciences, Université Ibn Zohr, Agadir, Morocco
}

(Accepted 30 March 2007)

\begin{abstract}
The aim of this study was to find an alternative to the chemical fungicides currently used in the control of postharvest citrus fruit diseases. Here we screened twenty-one medicinal and aromatic plants used in southern Moroccan traditional medicine for their activity against Penicillium digitatum, Penicillium italicum and Geotrichum candidum. The antifungal efficacy of powders, essential oils and solvent extracts of these plants was tested in vitro by using the agar plates method. Our results show that among the 21 plants tested, the powders of Thymus leptobotrys, Cistus villosus and Peganum harmala plants totally inhibited the growth of all three pathogens. Furthermore, the powder of the Eucalyptus globulus plant totally inhibited the mycelial growth of both G. candidum and $P$. digitatum, whereas the powders of Juglans regia and Myrtus communis plants completely inhibited the mycelial growth of G. candidum, and the powder of the Arenaria rubra plant totally inhibited the growth of the $P$. digitatum fungus. The essential oils, as well as the methanolic and chloroformic extracts of plants with the highest antifungal activity, were tested against the mycelial growth of the three pathogens. The results indicate that only the essential oils and the chloroformic extract of the T. leptobotrys plant totally inhibited the three pathogens. These results demonstrate that plant-derived products have a high potential to control fungal diseases of citrus fruits. Such biopesticides therefore represent a sustainable alternative to the use of chemical pesticides.
\end{abstract}

medicinal and aromatic plants / Citrus fruit / antifungal activity / Penicillium digitatum / Penicillium italicum / Geotrichum candidum / biopesticide

\section{INTRODUCTION}

During storage, fruits and vegetables are often subject to varying levels of microbial decay, mainly due to pathogenic fungi which usually infect the host through wounds sustained during harvest, handling and/or processing (El Ghaouth et al., 2002). In the case of citrus fruits, losses are mainly caused by Penicillium digitatum, Penicillium italicum and Geotrichum candidum (Eckert and Ogawa, 1985; Laville, 1971).

Currently, control of postharvest citrus diseases relies mainly on the use of synthetic fungicides, principally thiabendazole and imazalil, sprayed on fruit during waxing operations at packing facilities (Brown and Miller, 1999). The emergence of strains of pathogens resistant to these fungicides (Spotts and Cervanntes, 1986; Suhr and Nielsen, 2003; Eckert, 1987), as well as the growing concern for human safety and the protection of the environment (Suhr and Nielsen, 2003; Wilson et al., 1997), compel us to search for alternatives to the use of synthetic fungicides in the control of postharvest diseases. Biological control using naturally-occurring substances has been recently explored for managing postharvest decay of fruits. Because of their non-phytotoxicity and systemicity (Fawcett and Spencer, 1970), as well as biodegradability, plant-derived products can be potent and valuable reagents in pest management (Mishra and Dubey, 1990; Shukla and Tripathi, 1987; Tripathi and Dubey, 2004; Xuan et al., 2006; Javaid et al., 2006). For example, essential oils and other medicinal and aro-

*Corresponding author: hassanboubaker@yahoo.fr matic plant extracts have been suggested as possible means of controlling citrus postharvest rots (Wilson et al., 1997; Mari and Guizzardi, 1998; Chebli et al., 2003).

In this study, twenty-one medicinal and aromatic plants used in southern Moroccan traditional medicine were screened for their antifungal activity against the principal postharvest fungal pathogens of citrus fruits, i.e. Penicillium digitatum, Penicillium italicum and Geotrichum candidum.

\section{MATERIALS AND METHODS}

\subsection{Plant material}

Twenty-one fresh plant samples were collected from the Souss valley (Agadir, Morocco) during March and April of 2003 (Tab. I). Voucher specimens were identified, and were deposited in the herbarium of the laboratory of plant ecology, Faculty of Sciences, Ibn Zohr University, Agadir, Morocco. Different parts of the plants were used (stem, leaves, flowers and seeds). Tests were carried out with powders and essential oils, as well as methanolic and chloroformic extracts.

\subsection{Fungal cultures}

The fungi used in this study, Penicillium digitatum, Penicillium italicum and Geotrichum candidum, were isolated from decayed citrus fruits. The fungi were maintained on Potato 
Table I. Antifungal activity of twenty-one plant powders against three postharvest pathogens of citrus fruit.

\begin{tabular}{|c|c|c|c|c|}
\hline \multirow{2}{*}{ Plant species } & \multirow{2}{*}{ Part used } & P. digitatum & P. italicum & G. candidum \\
\hline & & \multicolumn{3}{|c|}{ Growth inhibition $^{\mathrm{a}}(\%)$} \\
\hline$\overline{\text { Arenaria rubra } \mathrm{L} .}$ & Whole & $100 \pm 0.0$ & $65 \pm 0.2$ & $79 \pm 0.4$ \\
\hline Artemesia reptans C.Sm. & Leaves + stem & $47 \pm 0.5$ & $37 \pm 0.3$ & $26 \pm 0.7$ \\
\hline Cistus villosus L. & Leaves + stem & $100 \pm 0.0$ & $100 \pm 0.0$ & $100 \pm 0.0$ \\
\hline Echium horridum Batt. & Leaves + stem & $79 \pm 1.1$ & $52 \pm 0.5$ & $30 \pm 0.3$ \\
\hline Eucalyptus globulus Labill. & Leaves + stem & $100 \pm 0.0$ & $67 \pm 0.2$ & $100 \pm 0.0$ \\
\hline Juglans regia $\mathrm{L}$. & Bark & $79 \pm 0.2$ & $72 \pm 0.1$ & $100 \pm 0.0$ \\
\hline Lavandula dentata $\mathrm{L}$. & Leaves + stem + flowers & $34 \pm 0.3$ & $26 \pm 0.3$ & $0.5 \pm 0.7$ \\
\hline Lavandula multifida L. & Leaves + stem + flowers & $17 \pm 0.3$ & $-3 \pm 0.1$ & $-16 \pm 0.6$ \\
\hline Lippia citriodora H.B.et K. & Leaves & $29 \pm 0.1$ & $27 \pm 0.1$ & $-2 \pm 0.3$ \\
\hline Marrubium vulgare L. & Leaves + stem + flowers & $47 \pm 0.1$ & $42 \pm 0.3$ & $18 \pm 0.5$ \\
\hline Mentha pulegium L. & Leaves + stem & $59 \pm 0.0$ & $21 \pm 0.4$ & $-15 \pm 0.7$ \\
\hline Mentha rotundifolia $\mathrm{L}$. & Leaves + stem & $59 \pm 0.9$ & $22 \pm 0.7$ & $-12 \pm 0.2$ \\
\hline Myrtus communis L. & Leaves + stem & $80 \pm 0.4$ & $55 \pm 0.4$ & $100 \pm 0.0$ \\
\hline Nigella sativa $\mathrm{L}$. & Seeds & $81 \pm 0.1$ & $27 \pm 0.1$ & $74 \pm 0.0$ \\
\hline Ononis natrix L. & Leaves + stem & $38 \pm 0.1$ & $41 \pm 0.4$ & $22 \pm 0.1$ \\
\hline Peganum harmala L. & Seeds & $100 \pm 0.0$ & $100 \pm 0.0$ & $100 \pm 0.0$ \\
\hline Rosmarinus officinalis L. & Leaves + stem & $56 \pm 0.3$ & $22 \pm 0.4$ & $8 \pm 0.2$ \\
\hline Ruta montana Mill. & Leaves + stem & $28 \pm 0.6$ & $31 \pm 0.5$ & $34 \pm 0.2$ \\
\hline Schinus molle L. & Leaves + stem + fruit & $47 \pm 0.3$ & $24 \pm 0.3$ & $44 \pm 0.3$ \\
\hline Thymus leptobotrys Murb. & Leaves + stem & $100 \pm 0.0$ & $100 \pm 0.0$ & $100 \pm 0.0$ \\
\hline Thymus pallidus Coss. & Leaves + stem & $38 \pm 0.1$ & $58 \pm 0.6$ & $45 \pm 0.3$ \\
\hline
\end{tabular}

${ }^{\text {a }}$ Values are means of three replicates \pm standard deviation. The negative values indicate a profungal activity against some fungi species.

Dextrose Agar plates at $5{ }^{\circ} \mathrm{C}$, with periodic transfers through citrus fruit to maintain the aggressiveness of the pathogen. A one-week-old culture of each fungus was used to inoculate the agar plates.

\subsection{Preparation of plant extracts and testing for antifungal activity}

The plant samples were first air-dried and ground, and 10 grams of powders of each sample were added to $100 \mathrm{~mL}$ of Potato Dextrose Agar medium. The resulting suspensions were stirred for $10 \mathrm{~min}$, autoclaved for $15 \mathrm{~min}$ and subsequently filtered through four layers of sterile cheesecloth before being dispensed into 9-cm diameter Petri dishes.

The essential oils of selected plants were obtained by $3 \mathrm{~h}$ of steam distillation of $50 \mathrm{~g}$ of fresh samples using a steam distillation apparatus. Due to concern that some of their components could be sensitive to high temperature, these oils were sterilized using two methods: autoclaving and ultra-filtration through $0.2-\mu \mathrm{m}$ pore diameter Millipore Swinex filters, before being added to Potato Dextrose Agar medium.

The methanolic and chloroformic extracts were obtained from ground dry samples. Fifty grams of each plant were methanol- and chloroform-extracted (375 mL each) for $24 \mathrm{~h}$ using a Soxhlet apparatus. The extracts were filtered and the solvent completely removed using a rotary evaporator.

The agar plates method was used to screen for antifungal activity. As described above, powders were tested at a concentration of $10 \%(\mathrm{w} / \mathrm{v})$. Methanolic and chloroformic extracts were prepared as described above, added to the Potato Dextrose Agar medium and then autoclaved for $15 \mathrm{~min}$. Plates with Potato Dextrose Agar with and without solvents were used as control. Agar plates were inoculated with one of the three fungal pathogens (P. digitatum, P. italicum or G. candidum), using a 5-mm diameter agar disk taken from one-week-old cultures, mycelial surface facing down. The agar plates were then incubated at $25{ }^{\circ} \mathrm{C}$ for six days. Radial growth was determined by measuring colony size along two perpendicular axes. The antifungal activity was expressed in terms of percentage of mycelial growth inhibition and calculated according to the following formula:

$\%$ mycelial growth inhibition $=$

$$
\frac{\text { Control diameter }- \text { Plant extract diameter }}{\text { Control diameter }} \times 100
$$

\section{RESULTS AND DISCUSSION}

\subsection{Effect of powders on mycelial growth}

The screening of the 21 plant powders for antifungal activity against the three fungal species Penicillium digitatum, Penicillium italicum and Geotrichum candidum uncovered significant antifungal activity of Thymus leptobotrys, Cistus villosus and Peganum harmala (Tab. I). The powders of these plants completely inhibited the mycelial growth of the three pathogens. Some other plant powders from Juglans regia, Eucalyptus globulus, Myrtus communis and Arenaria rubra inhibited mycelial growth by more than $50 \%$. The remainder of 
the plant powders tested exhibited much lower antifungal activities, and some even enhanced the mycelial growth of $G$. candidum. Of the three fungal species tested, Geotrichum candidum was clearly the most susceptible to inhibition, with six plant powders completely inhibiting its growth, whereas only five and three powders were efficient against $P$. digitatum and P. italicum, respectively (Tab. I). In a previous study, BautistaBanos et al. (2003) found that the powder of the Pithecellobium dulce plant at $20 \mathrm{~g} / \mathrm{L}$ inhibited not more than $58 \%$ of the mycelial growth of $P$. digitatum.

\subsection{Effect of essential oils}

The results shown in Figure 1 indicate that of the plant species tested, only the essential oil of T. leptobotrys at $1.2 \mathrm{~g} / \mathrm{L}$ had the highest fungistatic effect (100\%), compared with the essential oils of E. globulus, C. villosus and $P$. harmala, where the growth inhibition was less than $40 \%$ on the three fungal pathogens. The essential oil of T. leptobotrys inhibited all three pathogens to the same degree as the corresponding powder. Interestingly, the antifungal activity of $T$. leptobotrys essential oil was not heat-labile, as it was unaffected by autoclaving.

In a previous study, the antifungal active ingredient of essential oil derived from $T$. capitatus, a species closely related to T. leptobotrys, was characterized as carvacrol (Arras and Picci, 1986). Unlu et al. (2003) reported that thymol, carvacrol and borneol were the main components of Thymus pectinatus plant essential oil. An antimicrobial activity test carried out with fractions of the essential oil showed that the activity was mainly observed in those fractions containing thymol and carvacrol. Soylu et al. (2005) found that essential oils from Origanum syriacum and Foeniculum vulgare plants possessed strong antimicrobial activity against conidial germination and germ tube elongation of $P$. digitatum. Other studies demonstrated the antifungal effect of plant essential oils and encouraged the use of these natural products as an alternative to chemical fungicides for citrus fruit treatments (Aligiannis et al., 2001; Cosentino et al., 1999; Elgayyar et al., 2001; Mishra and Dubey, 1994; Shin and Kim, 2005).

\subsection{Effects of chloroformic and methanolic extracts}

The effects of chloroformic and methanolic extracts on the mycelial growth of the three pathogens are listed in Table II. As in the case of powder and essential oils, T. leptobotrys chloroformic and methanolic extracts exhibited a significant fungistatic activity, $100 \%$ inhibition of fungal growth by the chloroformic extract at a concentration of $0.3 \%(\mathrm{w} / \mathrm{v})$, and a $71-76 \%$ inhibition by the methanolic extract at a concentration of $1.5 \%(\mathrm{w} / \mathrm{v})$. Similarly, chloroformic and methanolic extracts of $P$. harmala tested at a concentration of $1 \%$ and $2 \%(\mathrm{w} / \mathrm{v})$, respectively, exhibited a pronounced activity against the three pathogens. Indeed, these extracts completely inhibited the mycelial growth of the $P$. digitatum and $P$. italicum pathogens, whereas the chloroformic extract allowed some residual G. candidum mycelial growth (88\% inhibition). In contrast, $C$. villosus and E. globulus chloroformic

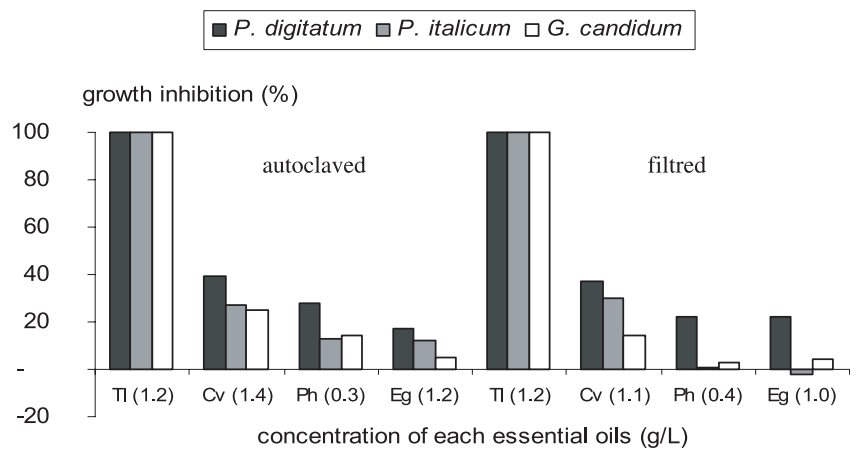

Figure 1. Effect of essential oils from Thymus leptobotrys (Tl), Cistus villosus $(\mathrm{Cv})$, Peganum harmala $(\mathrm{Ph})$ and Eucalayptus globulus (Eg) on mycelial growth of three pathogens using two methods of sterilization.

and methanolic extracts showed relatively lower inhibitory effects in comparison with their corresponding powders. The methanolic extracts allowed a $73 \%$ to $82 \%$ inhibition of $P$. digitatum and G. candidum mycelial growth, while the chloroformic extracts exhibited an inhibitory effect lower than 35\%.

Also of interest, we found that the methanolic extract of $P$. harmala was more effective than the chloroformic one, and at a low concentration $(1 \% \mathrm{w} / \mathrm{v})$. Shahverdi et al. (2005) have reported that the seeds of $P$. harmala were rich in alkaloid substances with antimicrobial activity. Therefore, the antimicrobial activity of these compounds against postharvest decay microorganisms of citrus fruits needs to be investigated.

The E. globulus and C. villosus methanolic extracts exhibited a potent antifungal activity against $P$. digitatum and $G$. candidum: mycelial growth was inhibited above $70 \%$. In contrast, the chloroformic extracts were less effective. The fungal growth inhibition was less than 35\%. Bouamama et al. (1999) reported the antibacterial and antifungal activities of leaf extracts obtained from two Moroccan Cistus species plants $(C$. villosus and $C$. monspeliensis) against five strains of bacteria and fungi. According to these authors, $C$. villosus extracts exhibited more activity than $C$. monspeliensis extracts.

In our study the methanolic extracts of E. globulus and $C$. villosus were more active against $P$. digitatum and G. candidum than the chloroformic extracts. Thus, it can be suggested that methanol is a better solvent for extraction of antifungal compounds from these two plant species. In the case of $P$. italicum, more studies are needed to explain the variation observed and to determine the nature of the active ingredients of these plants.

\section{CONCLUSION}

In the present study, we demonstrate that several Moroccan medicinal and aromatic plants possess potent antifungal activities with potential practical applications in the treatment of postharvest fungal diseases of citrus fruits. Among the 21 plants tested, T. leptobotrys, C. villosus, E. globulus and $P$. harmala showed high antifungal activities against the tested 
Table II. Antifungal activity of chloroformic and methanolic extracts of four medicinal plants against three postharvest pathogens.

\begin{tabular}{|c|c|c|c|c|c|}
\hline Plants & Type of extract & $\begin{array}{c}\text { Concentration } \\
(\% \mathrm{w} / \mathrm{v})\end{array}$ & P. digitatum & $\begin{array}{c}P . \text { italicum } \\
\text { Growth inhibition }{ }^{\mathrm{a}}(\%)\end{array}$ & G. candidum \\
\hline \multirow[t]{4}{*}{ Thymus leptobotrys } & Chloroformic & 0.1 & $68 \pm 0.1$ & $70 \pm 0.1$ & $26 \pm 0.0$ \\
\hline & & 0.3 & $100 \pm 0.0$ & $100 \pm 0.0$ & $100 \pm 0.0$ \\
\hline & Methanolic & 0.1 & $8 \pm 0.0$ & $9 \pm 0.1$ & $-5 \pm 0.2$ \\
\hline & & 1.5 & $73 \pm 0.1$ & $77 \pm 0.1$ & $71 \pm 0.0$ \\
\hline \multirow{4}{*}{ Eucalyptus globulus } & Chloroformic & 0.1 & $20 \pm 0.1$ & $6 \pm 0.1$ & $6 \pm 0.1$ \\
\hline & & 2.0 & $23 \pm 0.2$ & $16 \pm 0.1$ & $31 \pm 0.1$ \\
\hline & Methanolic & 0.1 & $18 \pm 0.2$ & $1 \pm 0.1$ & $18 \pm 0.0$ \\
\hline & & 0.7 & $73 \pm 0.1$ & $35 \pm 0.1$ & $82 \pm 0.1$ \\
\hline \multirow[t]{4}{*}{ Cistus villosus } & Chloroformic & 0.1 & $12 \pm 0.2$ & $3 \pm 0.1$ & $12 \pm 0.2$ \\
\hline & & 0.7 & $27 \pm 0.0$ & $27 \pm 0.1$ & $21 \pm 0.0$ \\
\hline & Methanolic & 0.1 & $15 \pm 0.1$ & $2 \pm 0.1$ & $12 \pm 0.1$ \\
\hline & & 0.8 & $77 \pm 0.0$ & $17 \pm 0.1$ & $79 \pm 0.0$ \\
\hline \multirow[t]{4}{*}{ Peganum harmala } & Chloroformic & 0.1 & $9 \pm 0.1$ & $6 \pm 0.1$ & $-1 \pm 0.2$ \\
\hline & & 2.0 & $100 \pm 0.0$ & $100 \pm 0.0$ & $88 \pm 0.0$ \\
\hline & Methanolic & 0.1 & $29 \pm 0.1$ & $16 \pm 0.1$ & $11 \pm 0.1$ \\
\hline & & 1.0 & $100 \pm 0.0$ & $100 \pm 0.0$ & $100 \pm 0.0$ \\
\hline
\end{tabular}

a All the values are means of three replicates \pm standard deviation.

pathogens. This antifungal activity was found in the plant powders, as well as in essential oils and solvent extracts. Plant powders showed a stronger antimicrobial activity than plant fractions. Further phytochemical research is needed to identify the active principles responsible for the antifungal effects of each plant and to make this a practical option for farmers' use.

\section{REFERENCES}

Aligiannis N., Kalpoutzakis E., Chinou I.B., Mitakou S., Gikas E., Tsarbopoulos A. (2001) Composition and antimicrobial activity of the essential oils of five taxa of Sideretis from Greece, J. Agr. Food Chem. 49, 811-815.

Arras G., Picci V. (1986) Attività fungistatica dell'olio essenziale di Thymus capitatus L., Ann. Fac. Agraria Un. Sassari 32, 151-157.

Bouamama H., Villard J., Benharref A., Jana M. (1999) Antibacterial and antifungal activities of Cistus incanus and C. monspeliensis leaf extracts, Therapie 6, 731-733.

Bautista-Banos S., Garcia-Dominguez E., Barrera-Necha L.L., ReyesChilpa R., Wilson C.L. (2003) Seasonal evaluation of the postharvest fungicidal activity of powders and extracts of huamuchil (Pithecellobium dulce): action against Botrytis cinerea, Penicillium digitatum and Rhizopus stolonifer of strawberry fruit, Postharvest Biol. Tec. 29, 81-92.

Brown G.E., Miller W.R. (1999) Maintaining fruit health after harvest, in: Timmer L.W., Duncan L.W. (Eds.), Citrus Health Management, APS Press, Minnesota, USA, pp. 175-188.

Chebli B., Achouri M., Idrissi Hassani L.M., Hmamouchi M. (2003) Chemical composition and antifungal activity of essentiel oils of seven Moroccan Labiatae against Botrytis cinerea Pers: Fr., J. Ethnopharmacol. 89, 165-169.

Cosentino S., Tuberoso C.I.G., Pisano B., Satta M., Mascia V., Arzedi E., Palmas F. (1999) In-vitro antimicrobial activity and chemical composition of Sardinian Thymus essential oils, Lett. Appl. Microbiol. 29, 130-135.
Eckert J.W. (1987) Penicillium digitatum biotypes with reduced sensitivity to imazalil, Phytopathology 77, 1728.

Eckert J.W., Ogawa J.M. (1985) The chemical control of postharvest diseases: Subtropical and tropical fruits, Annu. Rev. Phytopathol. 23, $421-454$

Elgayyar M., Draughon F.A., Golden D.A., Mount J.R. (2001) Antimicrobial activity of essential oils from from selected pathogenic and saprophytic microorganisms, J. Food Protect. 64, 1019-1024.

El Ghaouth A., Wilson C.L., Wisniewski M., Droby S., Smilanick J.L., Korsten L. (2002) Biological control of postharvest diseases of citrus fruits, in: Gnanamanickam S.S. (Ed.), Biological Control of Crop Diseases, University of Madras-Guindy Chennai, Tamil Nadu, India, pp. 291-312.

Fawcett C.H., Spencer D.M. (1970) Plant chemotherapy with natural products, Annu. Rev. Phytopathol. 8, 403-418.

Javaid I., Dadson R.B., Hashem F.M., Joshi J. (2006) Antibiosis of forage soybean as an ecological alternative for the control of corn earworm, Agron. Sustain. Dev. 26, 55-59.

Laville E. (1971) Evolution des pourritures d'entroposage des agrumes avec l'utilisation de nouveaux fongicides de traitement après récolte, Fruits 26, 301-304.

Mari M., Guizzardi M. (1998) The postharvest phase: Emerging technologies for the control of fungal diseases, Phytoparasitica 26, 5966.

Mishra A.K., Dubey N.K. (1990) Fungitoxicity of essential oil of Amomum subulatum against Aspergillus flavus, Econ. Bot. 44, 530533.

Mishra A.K., Dubey N.K. (1994) Evaluation of some essential oils for their toxicity against fungi causing deterioration of stored food commodities, Appl. Environ. Microb. 60, 1101-1105.

Shahverdi A.R., Monsef-Esfahani H.R., Nickavar B., Bitarafan L., Khodaee S., Khoshakhlagh N. (2005) Antimicrobial activity and main chemical composition of two smoke condensates from Peganum harmala seeds, Z. Naturforsch. 60, 707-710.

Shin S., Kim J.H. (2005) In vitro inhibitory activities of essential oils from two Korean Thymus species against antibiotic-resistant pathogens, Arch. Pharm. Res. 8, 897-901. 
Shukla H.S., Tripathi S.C. (1987) Antifungal substances in the essential oil of anise (Pimpinella anisum L.), Agr. Biol. Chem. 51, 1991-1993.

Soylu E.M., Tok F.M., Soylu S., Kaya A.D., Evrendilek G.A. (2005) Antifungal activities of the essential oils on postharvest disease agent Penicillium digitatum, Pakistan J. Biol. Sci. 8, 25-29.

Spotts R.A., Cervantes L.A. (1986) Populations, pathogenicity and benomyl resistance of Botrytis spp., Penicillium spp. and Mucor piriformis in packing houses, Plant Dis. 70, 106-108.

Suhr K.I., Nielsen P.V. (2003) Antifungal activity of essential oils evaluated by two different application techniques against rye bread spoilage fungi, J. Appl. Microb. 94, 1-11.
Tripathi P., Dubey N.K. (2004) Exploitation of natural products as an alternative strategy to control postharvest fungal rotting of fruit and vegetables, Postharvest Biol. Tec. 3, 235-245.

Unlu G.V., Candan F., Sokmen A., Daferera D., Polissiou M., Sokmen M., Donmez E., Tepe B. (2003) Antimicrobial and antioxidant activity of the essential oil and methanol extracts of Thymus pectinatus Fish. et Mey. Var. pectinatus (Lamiaceae), J. Agr. Food Chem. 51, 63-67.

Wilson C.L., El Ghaouth A., Solar J.M., Wisniewski M.E. (1997) Rapid evaluation of plant extracts and essential oils for fungicidal activity against Botrytis cinerea, Plant Dis. 81, 204-210.

Xuan T.D., Elzaawely A.A., Deba F., Fukuta M., Tawata S. (2006) Mimosine in Leucaena as a potent bio-herbicide, Agron. Sustain. Dev. 26, 89-97. 